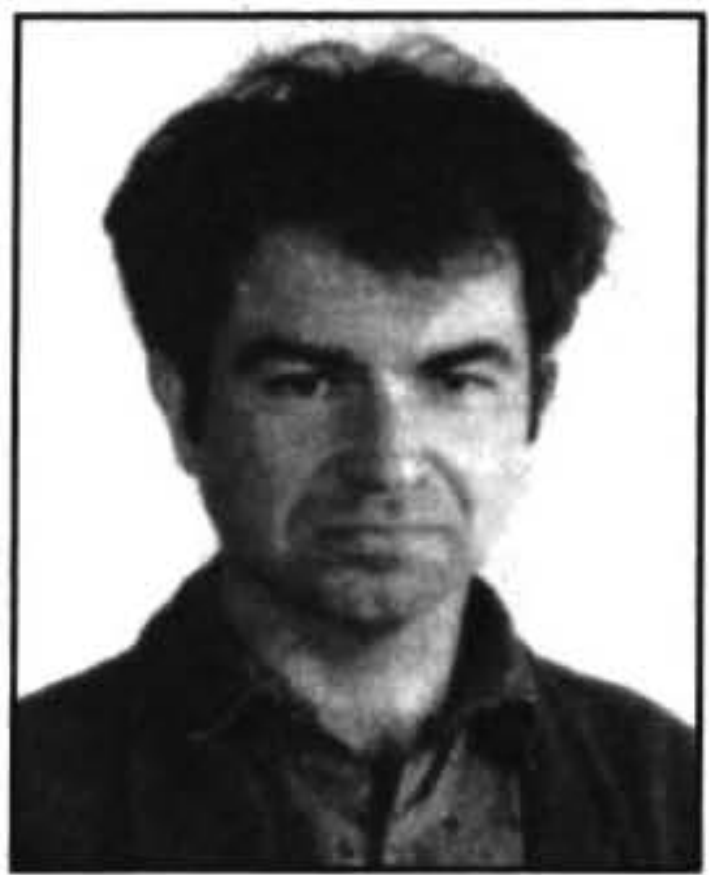

\title{
MAORI LITERACY: ITS INFLUENCE ON EARNINGS AND JOBS
}

\author{
Simon Chapple ${ }^{1}$
}

Ministry of Social Policy

\section{Abstract}

In terms of explaining the gap between Maori and non-Maori labour market outcomes, little attention has been given to literacy. Yet the 1977 New Zealand International Adult Literacy Survey showed that Maori tested English literacy was considerably lower than that of non-Maori in Prose, Document and Quantitative domains. The paper examines the links between Maori ethnicity, literacy and employment prospects and levels if earnings using cross-tabulations and multi-variate techniques on unit data.

Keywords: Literacy, Maori

Literacy issues are an increasing focus of labour market and education policy. At the same time there is considerable policy and research interest in closing the average socio-economic gaps between Maori and non-Maori (Chapple and Rea 1998; Chapple 1999, Chapple 2000).

The research questions this paper addresses are as follows. What are the descriptive differences in tested literacy between and within Maori and non-Maori populations? What are the main differences in other observed characteristics between sub-populations? Is there a significant impact of being Maori on earnings after controlling for literacy and other background variables? Is there a significant impact of being Maori on employment chances after controlling for literacy and other variables? Do higher levels of literacy impact on Maori in a different way from non-Maori? Finally, what are some potential explanations of the observed patterns?

This study uses Ministry of Education data from the International Adult Literacy Survey to address the research questions. The New Zealand part of the Adult Literacy Survey includes 4,223 New Zealanders aged between 16 and 65 (the data is available as a SAS data set). The data was collected in March 1996. The raw response rate was $75 \%$. There were $3,293(78 \%)$ fully completed and 930 partially completed unweighted responses $(22 \%)$. Unless otherwise indicated, all statistical data refers to the complete weighted responses only.

The Ministry of Education (no date), using information collected as part of the International Adult Literacy Survey, has extracted some key cross tabulations. These tabulations show that literate people are more likely to be employed than unemployed, earn higher incomes than less literate people, have better educational qualifications and are more likely to be of the European/Pakeha ethnic group.
The survey collects a variety of socio-economic information as well as numerical measures of three types of functional literacy in English: prose literacy, document literacy and quantitative literacy. The survey actually tests literacy rather than simply using the self-assessed literacy levels of the respondents. Prose literacy involves location and use of information from fiction and non-fiction texts, Document literacy involves location and use of information in timetables, graphs and charts, and Quantitative literacy involves applying arithmetic operations to numbers embedded in printed material. The survey's results are weighted to be representative of the New Zealand population in terms of gender, age, education, household size and community size.

One great advantage of the data set over other available labour market data sets is that it contains much richer information on proxies for human capital and signalling variables possessed by people, as well as some information on parental educational background, than other available data sets. For example the Household Labour Force Survey (HLFS), the main New Zealand source of labour market information, provides information only on age and highest education qualification. The main disadvantage of the Adult Literacy Survey data is that the sample is fairly small in comparison to the HLFS. The small sample restricts useful disaggregation. Nevertheless, at the most general level some disaggregation is attempted in the analysis.

\section{Descriptive Differences}

Socio-demographic information and literacy scores are tabulated below for non-Maori, the Maori ethnic group, the sole Maori group (those with only Maori ethnicity), the mixed Maori group (those who report their ethnicity as Maori and another ethnic group). Below some group differences of interest are drawn out. 
The cross tabulations in Table 1 shows that Maori literacy is on average 13 percent lower than non-Maori. But, as measured by the standard deviation, the spread of nonMaori and Maori literacy outcomes is such that there is also substantial overlap between the two broad ethnic groups. Maori ethnicity is not non-literate destiny, much as it is not labour market status or earnings destiny. The average Maori shortfall is greatest in terms of document literacy (14 percent) and least in terms of prose literacy (11 percent).

Maori earn less: their annual income 28 percent less than non-Maori. Maori are less likely to be employed and more likely to be unemployed or out of the labour force, again not surprising in terms of data we already have from the HLFS (Chapple and Rea 1998). Maori are five years younger on average and average one year less of schooling than non-Maori. Maori also work three fewer weeks of the year on average. If they are working, Maori work roughly the same number of hours as non-Maori. Maori are much less likely to be tertiary educated: only 9 percent of Maori have a tertiary qualification compared to 29 percent of non-Maori.

Only 8 percent of the Maori ethnic group had Maori as their first language -5 percent of mixed Maori and 10

\section{Table 1. Descriptive Statistics for Maori and non-Maori}

(Standard Deviations in Brackets for the Non-binary Variables)

\begin{tabular}{|c|c|c|}
\hline Variable & Maori & Non-Maori \\
\hline Average literacy (out of 500) & $242(61.8)$ & $278(58.1)$ \\
\hline Prose literacy (out of 500) & $249(59.5)$ & $281(58.4)$ \\
\hline Document literacy (out of 500 ) & $238(66.8)$ & $276(60.9)$ \\
\hline Quantitative literacy (out of 500) & $240(64.3)$ & $276.9(59.6)$ \\
\hline Annual earnings & $\$ 15,547(\$ 20,000)$ & $\$ 21,661(\$ 23,637)$ \\
\hline Employed (\%) & 59.4 & 71.7 \\
\hline Unemployed (\%) & 14.4 & 5.2 \\
\hline Not in the labour force (\%) & 26.2 & 23.1 \\
\hline Full-time & 49.1 & 59.6 \\
\hline Weeks worked in the year & $41.6(17.2)$ & $44.8(14.5)$ \\
\hline Normal weekly hours & $36.6(17.7)$ & $36.2(16.4)$ \\
\hline Age in years & 33.1 & 38.5 \\
\hline Married (\%) & 45.6 & 60.8 \\
\hline Maori ethnic group (\%) & 100 & 0 \\
\hline Sole Maori ethnic group (\%) & 67.9 & 0 \\
\hline Pacific Island ethnic group (\%) & 0 & 4.5 \\
\hline Asian ethnic group (\%) & 0 & 5.4 \\
\hline Years of schooling & $11.1(2.3)$ & $12.1(2.8)$ \\
\hline Primary schooling only $(\%)$ & 2.8 & 1.8 \\
\hline Completed secondary school (\%) & 21.9 & 24.2 \\
\hline Tertiary educated $(\%)$ & 9.0 & 28.8 \\
\hline New Zealand born (\%) & 99.6 & 78.3 \\
\hline New Zealand born Asians (\%) & 0 & 0.6 \\
\hline New Zealand born Pacific Islanders (\%) & 0 & 2.2 \\
\hline First language Maori $(\%)$ & 8.2 & 0.1 \\
\hline First language Chinese (\%) & 0 & 2.0 \\
\hline First language Pacific Island (\%) & 0.4 & 2.3 \\
\hline Mother primary educated only (\%) & 15.6 & 13.9 \\
\hline Mother tertiary education (\%) & 5.7 & 14.2 \\
\hline Mother education unknown (\%) & 29.6 & 18.9 \\
\hline Father primary education (\%) & 19.0 & 14.5 \\
\hline Father tertiary education (\%) & 8.3 & 19.3 \\
\hline Father education unknown (\%) & 38.9 & 20.2 \\
\hline Eye problems at school (\%) & 14.5 & 10.5 \\
\hline Hearing problems at school $(\%)$ & 14.4 & 12.4 \\
\hline Talking problems at school $(\%)$ & 6.8 & 5.2 \\
\hline Learning difficulties at school (\%) & 9.3 & 6.9 \\
\hline Other disabilities at school (\%) & 19.7 & 15.5 \\
\hline Eye problems cured $(\%)$ & 3.3 & 2.1 \\
\hline Hearing problems cured $(\%)$ & 3.2 & 2.2 \\
\hline Talking problems cured (\%) & 3.4 & 3.4 \\
\hline Learning difficulties cured (\%) & 3.4 & 2.5 \\
\hline Other disabilities cured (\%) & 3.6 & 3.1 \\
\hline
\end{tabular}


percent of sole Maori.

Maori parents have lower education attainments relative to non-Maori. It should be noted that, because of high rates of inter-marriage, a considerable number, at least a third but perhaps more, of Maori parents are members of the non-Maori ethnic group. Maori parents are two or three times less likely to be tertiary educated than non-Maori parents. In addition, Maori respondents are much less likely to know the highest level of parental education. Almost forty percent of Maori do not know their father's highest level of education compared to only twenty percent of non-Maori. This may well reflect higher rates of sole parenting by mothers among Maori.

Finally Maori typically appear to be somewhat more likely to have disabilities while at school.

Maori have been defined above as all those who respond as Maori, regardless of other ethnic affiliations. Giving an arbitrary primacy to Maori ethnic affiliation is the standard Statistics New Zealand prioritised approach to defining ethnicity. Splitting out from the Maori ethnic group those who respond only Maori (sole Maori) and those who respond Maori and another ethnic group (mixed Maori, about a third of the Maori ethnic group) reveals substantial group differences amongst the conventionally defined Maori ethnic group, as shown in Table 2.

The literacy gap relative to non-Maori is three times larger for the sole Maori group ( 17 percent) than for the mixed Maori group ( 5 percent). Mixed Maori income is 85 percent of non-Maori, compared to 66 percent for sole Maori. Mixed Maori are much more likely to be working and less likely to be unemployed. They work more than four weeks a year on average compared to sole Maori. Mixed Maori have more years of schooling and achieve a higher level of education on average, with over double the proportion tertiary educated compared to sole Maori.

Finally mixed Maori parents are likely to be better educated and the mixed group are much more likely to know their parents' highest education level than sole Maori. For example 27 percent of mixed Maori do not know their father's highest level of education, compared to 20 percent for non-Maori, a 7 percentage point difference. For sole Maori on the other hand the figure is 45 percent, a 25 percentage point difference compared to non-Maori. About 20 percent of non-Maori and of mixed Maori do not know their mother's highest level of education, compared to over a third of sole Maori.

On most socio-demographic dimensions mixed Maori perform more like non-Maori than like the sole Maori group. This evidence reinforces earlier work undertaken which questions the automatic aggregation of the mixed and sole Maori groups as one for social science purposes, a practice encouraged by Statistics New Zealand's prioritised classification of ethnic groups (Chapple and Rea 1998).

\section{Literacy and Earnings}

This section examines earnings and employment disparity between sole Maori, mixed Maori and non-Maori using the literacy data set. The approach does not attempt a full Blinder/Oaxaca decomposition. Rather, using dummy variables for mixed and sole Maori, it considers the evolution of the size and significance of the ethnicity dummies as additional socio-demographic variables, including literacy, are added to the regressions. The approach is similar to a decomposition if the manner by which the socio-demographic variables translate into earnings does not differ significantly between the broad ethnic groups considered.

Consider the simplest regression seeking to explain annual earnings variation only by mixed and sole Maori ethnicity (Tables 1 and 2, first columns). There is a considerable average gap, between a quarter and a third on annual earnings, for both female and male sole Maori. In both cases this sole Maori gap is statistically significant. On the other hand the income gap is actually positive for mixed Maori males but is not significantly different from non-Maori. The negative gap for mixed Maori females is not statistically significant. Of particular interest is the small explained variation of earnings regressions using only Maori ethnicity variables. The fits in both cases were less than one percent. This low explained variation shows that Maori ethnicity is not earnings destiny. Intra Maori and intra non-Maori earnings variation is far greater than inter-ethnic group variation. There are many high earning Maori as well as low earning non-Maori. This point is regularly omitted from disparity discussions that focus simply on average Maori outcomes relative to nonMaori outcomes.

Adding age and marital status to the regression reduces the sole Maori earnings gap by roughly a third for both men and women (Tables 3 and 4, second columns). The gap remains significant for sole Maori men but loses significance for sole Maori women. The gap falls by a much larger amount - 60 percent - for mixed Maori women and remains insignificant. The male mixed Maori earnings advantage increases, but is still not significant. Further adding education reduces the raw male sole Maori gap to about half its original level and the female sole Maori gap becomes positive (Tables 3 and 4, columns). In both cases the gap loses significance. Adding literacy makes gaps somewhat smaller, more so for women than for men. In both cases the mixed Maori earnings gap is positive but not significant. Finally, in the right most column quantity controls are added for the amount of the year worked, full-time employment status and normal weekly hours allowing consideration of earnings per unit time. The earnings gap is mildly positive for both mixed and sole Maori men and mildly negative for mixed and sole Maori women. In no case is it statistically significant. 
Table 2. Descriptive Statistics for Mixed Maori and Sole Maori

(Standard Deviations in Brackets for the Non-binary Variables)

\begin{tabular}{|c|c|c|}
\hline Variable & Mixed Maori & Sole Maori \\
\hline Average literacy (out of 500) & $264(51.5)$ & $232(64.3)$ \\
\hline Prose literacy (out of 500) & $271(50.3)$ & $238(61.0)$ \\
\hline Document literacy (out of 500) & $260(56.0)$ & $228(69.8)$ \\
\hline Quantitative literacy (out of 500) & $261(53.7)$ & $230(67.3)$ \\
\hline Annual earnings & $\$ 18,319(\$ 18,790)$ & $\$ 14,203(\$ 20,605)$ \\
\hline Employed (\%) & 71.7 & 53.6 \\
\hline Unemployed (\%) & 3.8 & 19.4 \\
\hline Not in the labour force $(\%)$ & 24.4 & 27.0 \\
\hline Full-time & 54.8 & 46.5 \\
\hline Weeks worked in the year & $44.4(13.8)$ & $40.0(19.1)$ \\
\hline Normal weekly hours & $35.7(17.8)$ & $37.1(17.6)$ \\
\hline Age in years & $33.3(11.6)$ & $33.0(14.0)$ \\
\hline Married (\%) & 50.1 & 43.5 \\
\hline Maori ethnic group (\%) & 100 & 100 \\
\hline Sole Maori ethnic group (\%) & 0 & 100 \\
\hline Pacific Island ethnic group (\%) & 0 & 0 \\
\hline Asian ethnic group (\%) & 0 & 0 \\
\hline Years of schooling & $11.5(2.5)$ & $10.9(2.2)$ \\
\hline Primary schooling only (\%) & 0 & 4.1 \\
\hline Completed secondary school (\%) & 25.6 & 20.1 \\
\hline Tertiary educated $(\%)$ & 15.2 & 6.0 \\
\hline New Zealand born (\%) & 100 & 99.4 \\
\hline New Zealand born Asians (\%) & 0 & 0 \\
\hline New Zealand born Pacific Islanders (\%) & 0 & 0 \\
\hline First language Maori (\%) & 5.0 & 9.6 \\
\hline First language Chinese (\%) & 0 & 0 \\
\hline First language Pacific Island (\%) & 1.2 & 0 \\
\hline Mother primary educated only (\%) & 17.2 & 14.8 \\
\hline Mother tertiary education (\%) & 9.4 & 4.0 \\
\hline Mother education unknown (\%) & 19.5 & 34.4 \\
\hline Father primary education only (\%) & 16.0 & 20.4 \\
\hline Father tertiary education (\%) & 15.9 & 4.7 \\
\hline Father education unknown (\%) & 26.5 & 44.7 \\
\hline Eye problems at school (\%) & 19.6 & 12.1 \\
\hline Hearing problems at school (\%) & 14.1 & 14.5 \\
\hline Talking problems at school $(\%)$ & 11.0 & 4.8 \\
\hline Learning difficulties at school (\%) & 6.8 & 10.5 \\
\hline Other disabilities at school (\%) & 16.7 & 21.1 \\
\hline Eye problems cured $(\%)$ & 6.1 & 2.0 \\
\hline Hearing problems cured $(\%)$ & 3.7 & 3.1 \\
\hline Talking problems cured (\%) & 4.6 & 2.8 \\
\hline Learning difficulties cured (\%) & 1.0 & 4.5 \\
\hline Other disabilities cured (\%) & 4.2 & 3.4 \\
\hline
\end{tabular}

\section{Literacy and Employment Status}

Now consider disparity in employment chances. In the rawest regression of mixed and sole Maori dummy variables, a significant employment gap exists only for sole Maori. There is no significant gap for mixed Maori (Table 5 and 6 , first columns). Age and marriage controls explain 25 percent of the male sole Maori gap but only 6 percent of the corresponding female gap (Table 5 and 6 , second columns). Adding literacy to explain male Maori employment disparity after controlling for age, martial status and education reduces it from a significant 10 percent gap to an insignificant 5 percent gap. Adding literacy to explain the female Maori gap reduces it by 5.4 per- centage points but it remains statistically significant. (Table 5 and 6 , fourth columns).

Further information of interest is presented in Table 7 , which run separate simple regressions splitting the population up into sub-groups by highest educational qualification. These sub-regressions show that the significant aggregate employment gap is driven by sole Maori with low educational qualifications. Sole Maori with tertiary and completed secondary school have employment outcomes much more like those of their non-Maori counterparts. On the other hand sole Maori with only some secondary education have very low chances of employment relative to non-Maori. Adding controls for age, gender, 
Table 3. Evolution of the Male Maori/non-Maori Percentage Annual Earnings Gap

(Percentages in Bold Indicate a Gap Which is Significant at a Five Percent Level)

\begin{tabular}{lccccc}
\hline & $\mathbf{1}^{\text {st }}$ equation & $\mathbf{2}^{\text {nd }}$ equation & $\mathbf{3}^{\text {rd }}$ equation & $4^{\text {th }}$ equation & $\mathbf{5}^{\text {th }}$ equation \\
\hline Sole Maori \% gap & $\mathbf{- 3 2 . 6}$ & $\mathbf{- 2 1 . 9}$ & -16.2 & -15.2 & +4.4 \\
Mixed Maori \% gap & +8.9 & +13.4 & +13.9 & +14.3 & +1.7 \\
Age, married & No & Yes & Yes & Yes & Yes \\
Education variables & No & No & Yes & Yes & Yes \\
Literacy variables & No & No & No & Yes & Yes \\
Quantity variables & No & No & No & No & Yes \\
$\mathrm{R}^{2}$ & 0.007 & 0.390 & 0.404 & 0.418 & 0.655 \\
\hline
\end{tabular}

Table 4. Evolution of the Female Maori/non-Maori Percentage Annual Earnings Gap

(Percentages in Bold are Significant at a Five Percent Level)

\begin{tabular}{lccccc}
\hline & $\mathbf{1}^{\text {st }}$ equation & $\mathbf{2}^{\text {nd }}$ equation & $\mathbf{3}^{\text {rd }}$ equation & $\mathbf{4}^{\text {th }}$ equation & $\mathbf{5}^{\text {th }}$ equation \\
\hline Sole Maori \% gap & $\mathbf{- 2 7 . 2}$ & -19.5 & -5.7 & +5.3 & -4.5 \\
Mixed Maori \% gap & -23.0 & -9.4 & -0.1 & +4.3 & -1.1 \\
Age, married & No & Yes & Yes & Yes & Yes \\
Education variables & No & No & Yes & Yes & Yes \\
Literacy variables & No & No & No & Yes & Yes \\
Quantity variables & No & No & No & No & Yes \\
$\mathrm{R}^{2}$ & 0.005 & 0.120 & 0.167 & 0.192 & 0.641 \\
\hline
\end{tabular}

Table 5. The Male Maori/non-Maori Employment Rate Disparity

(Marginal Effects from a Logistic Model, Percentages in Bold are Significant at a Five Percent Level)

\begin{tabular}{lcccc}
\hline & $\mathbf{1}^{\text {st }}$ equation & $\mathbf{2}^{\text {nd }}$ equation & $\mathbf{3}^{\text {rd }}$ equation & $\mathbf{4}^{\text {th }}$ equation \\
\hline Sole Maori \% gap & $\mathbf{- 1 6 . 3}$ & $\mathbf{- 1 2 . 3}$ & $-\mathbf{9 . 7}$ & -5.4 \\
Mixed Maori \% gap & +3.9 & +2.1 & +2.7 & +3.9 \\
Age, married & No & Yes & Yes & Yes \\
Education variables & No & No & Yes & Yes \\
Literacy variables & No & No & No & Yes \\
\hline
\end{tabular}

Table 6. The Female Maori/non-Maori Employment Rate Disparity

(Marginal Effects from a Logistic Model, Percentages in Bold are Significant at a Five Percent Level)

\begin{tabular}{lcccc}
\hline & $\mathbf{1}^{\text {st }}$ equation & $\mathbf{2}^{\text {nd }}$ equation & $\mathbf{3}^{\text {rd }}$ equation & $\mathbf{4}^{\text {th }}$ equation \\
\hline Sole Maori \% gap & $\mathbf{- 1 9 . 7}$ & $\mathbf{- 1 8 . 5}$ & $\mathbf{- 1 4 . 4}$ & $\mathbf{- 9 . 0}$ \\
Mixed Maori \% gap & +0.0 & +0.1 & +2.8 & +3.7 \\
Age, married & No & Yes & Yes & Yes \\
Education variables & No & No & Yes & Yes \\
Literacy variables & No & No & No & Yes \\
\hline
\end{tabular}


marital status and literacy (all of which were significant at a five percent level) to a regression considering employment chances of those with some secondary education reduced the $21.3 \%$ employment gap for sole Maori with some secondary qualifications by $43 \%$ to $12.2 \%$. At the same time the sole Maori coefficient for those with some secondary qualifications remained statistically significant at a five percent level. Table 7 also shows that mixed Maori gaps across educational qualifications were not significant and were fairly small.

Further simple regressions in Table 8 explaining employment outcomes separately in rural and urban areas by mixed and sole Maori binary variables shows that employment rate gaps are considerably greater for sole and mixed Maori who live in rural areas. For sole Maori in rural areas the employment rate gap is nearly three times of that of their urban cousins (a thirty percent employment rate gap). Adding controls again age, gender, marital status and literacy reduced the $30.3 \%$ employment gap for rural sole Maori with some secondary qualifications to $-19.7 \%$, still very large. The sole Maori coefficient remained statistically significant at a five percent level. The rural mixed Maori gap fell from $-15.0 \%$ to $-3.1 \%$ and was no longer significant. In urban areas, the additional controls lowered the gap in employment chances to $-1.6 \%$ for sole Maori. For urban mixed Maori the gap was positive at $6.7 \%$. Neither urban Maori employment gap was significantly different from zero once additional controls were added. Again, there seem to be subtle dimensions to the gap - sole Maori without qualifications in rural areas are people amongst whom gaps are concentrated.

Another comparison of interest emerges from regressions separately explaining Maori and non-Maori employment prospects. The elasticity on literacy for Maori is significant and double in size compared to that for non-Maori. A ten percent rise in literacy raises Maori employment chances by 3 percent, compared to only 1.5 percent for
non-Maori. While in both sub-samples the impact of the spread of literacy is negative, it is not significant for Maori. Being married is associated with a 23 percent higher chance of having a job for Maori compared to only 11 percent higher prospects for non-Maori. Maori women are much less likely to have a job relative to Maori men than are non-Maori women relative to non-Maori men. Being female reduces Maori women's employment prospects by 20 percent compared to 13 percent for non-Maori women. Being mixed Maori raises employment prospects by 9 percent compared to sole Maori, but this is not quite statistically significant at a five percent level. Maori whose first language is Maori have a 22 percent lower chance of having a job than other Maori. Finally being urban is significant for Maori employment, raising employment prospects by a stunning 16 percent, while urbanity does not matter for non-Maori employment prospects. The estimates from the full regression model are given in Table 9.

\section{Conclusion}

The conclusion is that Maori earn less and have lower employment chances than non-Maori because being Maori is correlated with a number of other variables - age, educational qualifications, and tested literacy - that better explain annual earnings. The question of why Maori have on average acquired fewer of the things that better explain earnings variation is an open one. Some discussion of why on average Maori may have fewer of these things is worthwhile.

The younger age structure of the Maori population is in part due to higher past and to a lesser extent current levels of Maori fertility. Another part of the younger age structure of Maori is due to the prioritised classification of ethnicity where mixed ethnicity Maori, likely the products of recent high rates of inter-marriage, are categorised into the Maori ethnic group.

\section{Table 7. Maori Employment Rate Disparity by Educational Qualification}

(Marginal Effects from a Logistic Model, Percentages in Bold are Significant at a Five Percent Level)

\begin{tabular}{lccc}
\hline & $\begin{array}{c}\text { Some secondary } \\
\text { education sub-sample }\end{array}$ & $\begin{array}{c}\text { Completed secondary } \\
\text { education sub-sample }\end{array}$ & $\begin{array}{c}\text { Tertiary education sub- } \\
\text { sample }\end{array}$ \\
\hline Sole Maori \% gap & $\mathbf{- 2 1 . 3}$ & -6.8 & +0.1 \\
Mixed Maori \% gap & +0.3 & -3.7 & +11.3 \\
\hline
\end{tabular}

\section{Table 8. Maori Employment Rate Disparity by Urban/Rural Location}

(From a Logistic Regression, Percentages in Bold are Significant at a Five Percent Level)

\begin{tabular}{lrr}
\hline & Rural areas & Urban areas \\
\hline Sole Maori \% gap & $\mathbf{- 3 0 . 3}$ & $\mathbf{- 1 1 . 5}$ \\
Mixed Maori \% gap & $\mathbf{- 1 5 . 0}$ & 5.9 \\
\hline
\end{tabular}




\begin{tabular}{|c|c|c|}
\hline Variable & Maori & Non-Maori \\
\hline Log average literacy & $0.303(0.147)$ & $0.153(0.050)$ \\
\hline Std. Dev. of literacy & $-0.199(0.424)$ & $-0.754(0.236)$ \\
\hline Age & $0.027(0.013)$ & $0.033(0.005)$ \\
\hline $\mathrm{Age}^{2}$ & $-0.000(0.000)$ & $-0.000(0.000)$ \\
\hline Married & $0.236(0.046)$ & $0.107(0.018)$ \\
\hline Female & $-0.198(0.045)$ & $-0.126(0.016)$ \\
\hline Urban & $0.161(0.044)$ & $0.020(0.019)$ \\
\hline Mixed Maori group & $0.091(0.046)$ & \\
\hline Pacific Island ethnic group & - & $0.111(0.090)$ \\
\hline Asian ethnic group & & $-0.094(0.043)$ \\
\hline Years of schooling & $0.007(0.083)$ & $-0.035(0.016)$ \\
\hline Years of schooling ${ }^{2}$ & $0.000(0.004)$ & $0.001(0.001)$ \\
\hline Primary education & $0.243(0.164)$ & $-0.192(0.063)$ \\
\hline Completed secondary & $0.018(0.055)$ & $-0.006(0.021)$ \\
\hline Tertiary education & $0.111(0.100)$ & $0.072(0.025)$ \\
\hline Mother primary education & $-0.180(0.064)$ & $0.012(0.027)$ \\
\hline Mother tertiary education & $0.039(0.102)$ & $-0.037(0.024)$ \\
\hline Mother no education response & $-0.102(0.057)$ & $-0.013(0.024)$ \\
\hline Father primary education & $0.083(0.066)$ & $-0.007(0.027)$ \\
\hline Father tertiary education & $-0.065(0.089)$ & $-0.064(0.022)$ \\
\hline Father no education response & $-0.016(0.054)$ & $-0.025(0.024)$ \\
\hline Eye problems at school & $0.052(0.070)$ & $0.022(0.028)$ \\
\hline Hearing problems at school & $-0.061(0.066)$ & $0.053(0.028)$ \\
\hline Talking problems at school & $0.219(0.127)$ & $-0.015(0.057)$ \\
\hline Learning difficulties at school & $-0.095(0.104)$ & $-0.084(0.039)$ \\
\hline Other disabilities at school & $-0.203(0.062)$ & $-0.120(0.023)$ \\
\hline Eye problems cured & $-0.225(0.128)$ & $-0.043(0.058)$ \\
\hline Hearing problems cured & $-0.194(0.126)$ & $-0.063(0.060)$ \\
\hline Talking problems cured & $-0.207(0.180)$ & $0.092(0.072)$ \\
\hline Learning difficulties cured & $-0.082(0.164)$ & $0.013(0.057)$ \\
\hline Other disabilities cured & $0.180(0.115)$ & $0.065(0.048)$ \\
\hline NZ born Pacific Islander & _ & $-0.026(0.093)$ \\
\hline NZ born Asian & & $0.059(0.099)$ \\
\hline First language Maori & $-0.220(0.073)$ & \\
\hline First language Chinese & - & $-0.214(0.063)$ \\
\hline First language Pacific Island & - & $-0.353(0.088)$ \\
\hline
\end{tabular}

In terms of lower average Maori educational and literacy attainment, one obvious explanation is in the known strong inter-generational auto-correlation in education and literate skills. This merely pushes the explanation of lower Maori average education and literacy back one generational remove. Poor average Maori parental education and literacy outcomes could have been due to low quality education in the Native School system, cultural barriers in the education system of a generation or more ago, and the fact that for many Maori grandparents English would not have been a first language. In addition there were low incentives to acquire education and skills up until the mid-1970s when skill differential in the labour market were small and blue collar jobs plentiful. There may have been limited Maori financial resources available to acquire education and literacy due to patterns of land and other resource loss. At the same time, some of these issues may be ongoing, rather than simply being echoed in the current generation through the disadvantage of previous generations.

\section{Future Research}

The research has revealed a greater gap for sole Maori living outside urban areas without education and with low levels of literacy. One should be wary of reading too much in the way of causality into this combination, but it does indicate that much of the differences in aggregate Maori and non-Maori outcomes can be attributed to a sub-population of the Maori ethnic group. The evidence that Maori get a greater rate of return on their employment chances from literacy also suggests the possibility that providing the opportunity to acquire literacy could be a powerful lever to improve outcomes for disadvantaged Maori people. Again some investigation as to why Maori returns on literacy appear to be higher would be of considerable 
value. Is it, as John Gibson has suggested, due to family resource constraints?

The problem is not that there are no explanations for the observed facts. Rather the problem is that there are too many explanations and one cannot readily distinguish between them using currently available information. Further work in this area to articulate and test hypotheses would be valuable.

\section{Notes}

1 The paper was primarily written while I was a Senior Research Analyst in the Labour Market Policy Group, Department of Labour. The analysis and opinions presented in this paper are my own and should not be attributed in any way to my past or my current employer, the Ministry of Social Policy. E-mail:

Simon.Chapple006@mosp.govt.nz.

2 Interestingly, the survey also collected respondents' subjective assessments of their reading, writing and mathematical ability. A simple regression showed that these self-assessments explained only 24 percent of the variance of average tested literacy across the three domains.

3 The following procedure was used to calculate earnings for these tables. There are twelve earnings ranges in the literacy survey (no income, $<\$ 3,000$, $\$ 3,001-\$ 8,000, \$ 8,001-\$ 13,000, \$ 13,001-\$ 18,500$, $\$ 18,501-\$ 34,000, \$ 34,001-\$ 40,000, \$ 40,001$ $\$ 50,000, \$ 50,001-\$ 70,000, \$ 70,001-\$ 100,000$, $\$ 100,001>$ ). Individuals were assigned an income in the mid-point of each of the twelve income ranges. For the open ended top income range, an average income of $\$ 136,000$ was assigned using information from the Household Economic Survey and the Income Supplement of the HLFS. Thanks to Sylvia Dixon for extracting this median value. The results were not sensitive to this figure. Only a small number -39 in total - of individuals were in this income range.

\section{References}

Chapple, S. and Rea, D. (1998) Time Series Analysis of Disparity between Maori and non-Maori Labour Market Outcomes in the Household Labour Force Survey, Labour Market Bulletin. 1\&2: 127-144.

Chapple, S. (1999) Explaining Patterns of Disparity between Maori and non-Maori Employment Chances. Labour Market Bulletin, Forthcoming.

Chapple, S. (2000) Maori Socio-economic Disparity., New Zealand Journal of Political Science, Forthcoming, December.
Human Resources Development Canada (1997) Literacy Skills for the Knowledge Society. OECD/ Human Resources Development Canada.

Ministry of Education (no date), Adult Literacy in New Zealand. Results for the International Adult Literacy Survey. Ministry of Education.

\section{Author}

\author{
Simon Chapple \\ Chief Economist \\ Ministry of Social Policy \\ Private Bag 39993 \\ Wellington \\ Simon.Chapple006@mosp.govt.nz
}

